\section{El problema de lo documental: de la pretensión de objetividad a una aspiración estética y poética de la realidad ${ }^{1}$}

DOI: https://doi.org/10.18566/comunica.n46.a08

Recibido: 30 de agosto de 2021

Aceptado: 3 de noviembre de 2021

\section{Resumen}

A mediados del siglo XX, el problema de la representación de la realidad se reconfigura a partir de los aportes del denominado giro lingüístico, cuyo mayor fundamento consistió en reivindicar la realidad como una construcción discursiva; en otras palabras, el lenguaje ya no se considera un simple instrumento para nombrar la realidad, sino que, por el contrario, se asume como la única manera de crearla. Por ello, no resulta casual que, a la par de este fenómeno, en otras áreas de la creación se presentaran fracturas, como lo que algunos teóricos han denominado el fin del arte, y, en el caso específico del cine, el surgimiento de la idea de no ficción como una forma de resignificar la noción de documental o de un cine de lo real. En consecuencia, el propósito de este artículo es demostrar cómo la idea de lo documental permite emancipar el cine de lo real de su premisa clásica de pretender retratar fielmente la realidad para asumirla como un acto poético y estético; es decir, un acto discursivo.

\section{Abstract}

By the mid $20^{\text {th }}$ century, the linguistic turn contributed to reshape the problem of representation of reality, its main foundation was to claim reality as a discursive construction, in other words, language it is not anymore just a simple instrument to name reality otherwise it is assumed as the only way to create it. Therefore, it is not casual that parallel with this phenomenon comunicación

número 46

Enero-junio

2022 | pp.128-142

\section{Adriana}

Mora Arango

Doctora en Humanidades.

Profesora titular de la

Facultad de Comunicación

Social - Periodismo,

Universidad Pontificia

Bolivariana. Miembro del

Grupo de Investigación en

Comunicación Urbana (GICU),

categoría A de Colciencias.

https://orcid.org/0000-0002-

0774-9677

adriana.moraa@upb.edu.co

\section{Harold}

\section{Salinas Arboleda}

Magister en Estudios

Humanísticos. Profesor

titular de la Facultad de

Comunicación Social -

Periodismo, Universidad

Pontificia Bolivariana.

Miembro del Grupo

de Investigación en

Comunicación Urbana (GICU), categoría A de Colciencias.

https://orcid.org/0000-0003-

4433-4240

harol.salinas@upb.edu.co

1 Este texto presenta una reflexión realizada en el marco del proyecto de investigación titulado El concepto de la realidad en el cine documental, financiado por el Centro de Investigación para el Desarrollo y la Innovación (CIDI) de la Universidad Pontificia Bolivariana y adscrito al Grupo de Investigación en Comunicación Urbana (GICU). Asimismo, incluye ideas tomadas de la tesis El Desprendimiento de la realidad: 
there were other ruptures in different areas of creation, like some theorists have called the end of Art and specifically with cinema it was the emergence of the idea of nonfiction as a way of re-signifying the notion of documentary or a cinema of reality. Therefore, the purpose of this paper is to demonstrate how the idea of documentary allows the cinema to emancipate itself from its classic premise, pretending the faithful portrayal of reality presuming as a poetic and aesthetic act, which means as a discursive act.

\section{Introducción}

La pregunta por la realidad y los límites de su representación ha sido un común denominador presente no solo a lo largo de diferentes períodos históricos, sino en diversos campos del saber. Este cuestionamiento sigue vigente hoy, cuando los límites entre las manifestaciones estéticas y artísticas son cada vez más difusos. En este sentido, este texto revisa la relación entre lo que se entiende por realidad y la idea común de que en el ámbito cinematográfico el documental es el aparato estético responsable de registrarla fiel y objetivamente, para, de nuestra parte, sostener que tal pretensión se ha erosionado a tal punto que hoy la pregunta muda de lugar.

Para entender cuál puede ser ese lugar planteamos que en los inicios del siglo Xx se conjugan dos elementos que ponen en crisis la idea de representación y, por tanto, la idea de realidad: por un lado, los cambios de perspectiva en los estudios del lenguaje que la asumen como una construcción discursiva y, por el otro, las vanguardias artísticas, cuyas obras revelan una especie de hastío y desilusión frente a la imposibilidad de la representación en sí misma, y que conciben la producción artística más bien como una construcción simbólica cuya pretensión ya no se halla en el reflejo fiel del mundo, sino en una lectura simbólica del mismo.

Así pues, el texto revisa momentos específicos del siglo xx para demostrar que los elementos mencionados no solo se consolidan a lo largo del siglo, sino que cada vez se declaran de forma más explícita, a tal punto que hoy, en lo corrido del siglo XXI, asumimos que el documental se aproxima a la idea de realidad como el resultado de un acto estético y poético cuyo propósito no es ya retratar los hechos de manera incuestionable, sino ofrecer múltiples puntos de vista, múltiples subjetividades, que dependen del ojo documentalista que la observa.
129

Comunicación

número 46

Enero-junio

2022

el cambio de paradigma en las imágenes de lo documental presentada por la profesora Adriana Mora Arango (2021) para optar al título de Doctora en Humanidades de la Universidad EAFIT.

\section{Palabras clave}

Documental, Realidad, Lenguaje, Giro lingüístico, Representación.

\section{Key words}

Documentary, Reality, Language, Linguistic turn, Representation. 


\section{Del positivismo decimonónico a las nuevas formas de representación}

La tradición dominante de Occidente, desde el cartesianismo hasta el positivismo decimonónico, privilegió la razón como vía por excelencia para acceder a una única verdad cuya validez radicaría en la posibilidad de la demostración objetiva de los hechos y del mundo. Bajo esta égida, como lo plantea Foucault (2007), Occidente construyó su manera de concebir el saber: un conocimiento, valga la reiteración, exento de polisemias y subjetividades. Esta ilusión de objetividad permeó todas las esferas del conocimiento, no solo a las denominadas ciencias de la naturaleza, sino que también influyó en las llamadas ciencias del espíritu, tanto que inclusive asuntos como el arte, la filosofia, la historia o la política, por mencionar solo algunos, se plegaron al modelo cartesiano para poder gozar del estatuto de ciencia.

Sin embargo, en medio de este panorama, la aparición de un pensador como Friedrich Nietzsche se convirtió en un punto de inflexión en la comprensión del mundo. El pensador alemán, gracias a sus pesquisas filológicas, retoma las ideas presocráticas de la imposibilidad de conocer el mundo en sí mismo, pues aquello que acordamos designar como "mundo" es el resultado de un acto creativo del lenguaje; en otros términos, el lenguaje es la única posibilidad de intentar dotar de sentido a aquello que por sí mismo carece de él. Como bellamente lo afirma Nietzsche: "Las verdades son ilusiones que se ha olvidado que lo son" (2011, p. 613). Esta idea sintetiza parte de nuestra cuestión: la puesta en entredicho de las categorías de verdad y realidad como consecuencia de la idea de un sujeto responsable de la construcción del sentido del mundo.

No obstante, no podemos soslayar el hecho fundamental de que tales disquisiciones, que en primera instancia podrían ser vistas como abstracciones filosóficas o lingüísticas, hallan su concreción o se materializan en el terreno de la creación artística: nuestra propuesta es que las vanguardias de inicios del siglo xx son al arte lo que el lenguaje en el campo de la filosofía y la lingüística. ${ }^{2}$

La incertidumbre frente a los profundos cambios y la inestabilidad en todos los ámbitos de la vida social con los que inicia el siglo xx, lo que va en contravía de las utopías propuestas por el pensamiento moderno positivista en cuanto a sus paradigmas de progreso y bienestar, se convirtieron en terreno fecundo para el surgimiento de manifiestos y posturas estéticas que, en dicha medida, dieron paso a la consolidación de las propuestas de vanguardia que pusieron en entredicho la razón cartesiana e introdujeron la pregunta por los límites de la representación y la existencia de una realidad incuestionable. La idea de realidad positiva que es capaz de engendrar en su límite, en su colmo, la destrucción propia que genera la guerra revela

2 Inclusive, como comentario al margen, en el terreno de las ciencias exactas podría afirmarse que el correlato de esta nueva perspectiva estaría en planteamientos como la teoría de la relatividad de Einstein. 
no solo la crisis del positivismo, sino que instala la pregunta de si esa es la única realidad, lo único que puede ser representado, o si puede echarse mano de algo más que ofrezca una vía alternativa para dotar de sentido a aquello que nos rodea.

¿Qué es aquello, entonces, que puede dotar de sentido a un mundo que pareciera carecer de él? El acto creativo, estético, poético del lenguaje, responden los artistas de vanguardia. Un ejemplo claro de esto es la obra Ceci n'est pas une pipe (1929), de René Magritte. En el cuadro, que evidentemente representa una pipa, se lee el texto "Esto no es una pipa", que introduce una contradicción entre el mensaje lingüístico que acompaña la imagen y lo mostrado en ella, lo cual de entrada pone de relieve la imposibilidad de la representación explicativa, si se quiere veritativa, de acceso al mundo. Por tanto, de aquí se extrae la idea de que la noción de pipa es tan amplia o estrecha como el límite que la representación, entendida esta como una forma del lenguaje, le imponga. Es en este punto donde las vanguardias, en un intento por resignificar la función del arte, abandonan la pretensión de un arte exclusivamente figurativo para embarcarse en el problema cardinal de la representación simbólica del mundo.

\section{La reinvención de la imagen}

Frente al mismo problema de la representación, un antecedente que no debe dejarse de lado es la invención de la fotografia (a mediados del XIX) y posteriormente del cine (a finales del mismo siglo), que pusieron en el centro de los debates la cuestión por las posibilidades de representación de la realidad. Las discusiones al respecto tuvieron su lugar natural entre los artistas, especialmente los pintores, quienes fueron los primeros en sentirse interpelados por la llegada de estos artilugios mecánicos. Si se piensa en una tradición que había depositado en el artista la tarea de representar lo real (retratar a los nobles o a la naturaleza en sus mínimos detalles) es posible suponer que la usurpación hecha por esas nuevas tecnologías generó la ilusión de que por fin se estaba ante una copia fiel de la realidad, una huella irrefutable del mundo, pese a que décadas después se pudiera sostener, como lo afirma Susan Sontag, que "aunque lo que a los fotógrafos les interesa es sobre todo reflejar la realidad, sus fotografias son una interpretación del mundo tanto como lo son las pinturas y los dibujos" (2007, p. 20).

Ante esta idea de una realidad que puede ser capturada tal cual, el naciente cine reivindicó para sí (dadas las posibilidades técnicas de la cámara fotográfica, sumadas a la ilusión de movimiento) la pretensión de convertirse en el arte de lo real. De este modo, las imágenes de la llegada del tren a la estación de La Ciotat no solo representan el nacimiento del cine en su 
posibilidad de reproductibilidad técnica, sino que también son el inicio del debate sobre cuáles son los límites de esas imágenes y hasta qué punto lo que aparece alli es copia fiel de la realidad en sí misma. La posibilidad del registro fotográfico crea una impresión directa del mundo físico y configura una relación especular que condiciona a la imagen filmica; por lo tanto, la reproductibilidad técnica de la imagen per se, es decir, la cámara como dispositivo técnico externo al realizador, implicó la concepción de que por fin se cumplía el sueño de la captura directa de lo real.

Volvamos por un momento a la estación de La Ciotat. Si bien es indiscutible que las imágenes de la estación del tren captadas en 1895 por los hermanos Lumière son importantes en cuanto registro histórico de la vida cotidiana finisecular, al mirarlas con detenimiento es evidente que en ellas hay otros aspectos subyacentes que determinan esa secuencia fotográfica: la posición de la cámara, el punto de vista desde el cual se ve a los pasajeros y en el cual el tren entra a cuadro e, incluso, todos los elementos que quedan por fuera del campo visual. En esos 45 segundos de imágenes, el espectador se acerca a unos hechos en particular y se aleja de otros, y se hace una distribución del espacio y el tiempo que determina el impacto que producen aquellas, ante lo cual surge la pregunta de cuánto determina todo esto lo que queda en el registro: ¿sería igual si la misma escena se tomara desde otro ángulo, con otro encuadre?, ¿se estaría diciendo lo mismo, sería la misma realidad?

\section{Representación y subjetividad}

En medio del panorama que hasta aquí hemos esbozado frente a la pregunta por la representación y la realidad, abordemos otra arista de la discusión que nos sirve de clave para plantear lo que insinúa el título de este ensayo: que el problema de la realidad radica no en el objeto observado, sino en el punto de vista con el que el observador crea al objeto por medio de su discurso.

Los estudios contemporáneos sobre el lenguaje reconocen en Saussure al pensador que logró condensar en sus planteamientos buena parte de las intuiciones que transformaron la manera de concebir las relaciones entre el hombre, el mundo y el lenguaje desde los albores del xx (si pensamos en la primera edición de su Curso de lingüística general) hasta el presente. Para el tema que nos ocupa, baste recordar que mientras para las lingüísticas históricas del tiempo de Saussure el problema del lenguaje era trascendente, el gran aporte del pensador ginebrino consistió en plantear una postura inmanente en la cual la lengua, en cuanto manifestación del lenguaje, es un sistema que se explica a partir de la relación de sus elementos constitutivos entre sí y con el todo por medio de unas reglas que dan cuenta de su estructura. 
Entonces, el límite de una lengua es el límite de su estructura; y, por lo tanto, el alcance del lenguaje no es meramente referencial o mostrativo, sino que adquiere una dimensión creativa: lo dicho es en la medida en que precisamente ha sido dicho de una forma y no de otra.

El pensamiento del siglo xx es, en buena medida, resultado de la reconfiguración que propició el pensamiento saussureano no solo en el ámbito de los estudios del lenguaje, sino en las disciplinas o manifestaciones estéticas que tienen como pretensión preguntarse por la realidad, pues si ya la relación del lenguaje con el mundo no es entre una serie de cosas y una serie de nombres para esas cosas (es entre la cosa y el signo que la representa), entonces no habrá dominio de lo humano que no esté mediatizado por el lenguaje. En otros términos, toda representación (lingüística, pictórica, cinematográfica) es insuficiente en su pretensión de acceder al mundo material. Desde esta perspectiva, es perfectamente claro que para el arte vanguardista una pipa no sea una pipa.

\section{El objeto estético documental}

No obstante, en el cine, el problema de la realidad toma otro giro en 1926, cuando John Grierson decidió producir un tipo de películas que se aparta de lo que él consideraba artificios estéticos y narrativos propios de la ficción; dio nacimiento así a la expresión cine documental. Con el realizador inglés se introduce una especie de doble cuestionamiento sobre la realidad, puesto que este nuevo tipo de cine se comprometía a hacer, por un lado, películas que retrataran la realidad (dimensión mecánica) y que, además, se ocuparan de ella en cuanto fenómeno (dimensión ontológica), lo cual dio lugar a un discurso legitimador que estableció unos límites tanto de producción como conceptuales entre el cine de ficción y el cine documental.

Jean-Louis Déotte (2007) afirma que todo aparato estético suscita una sensibilidad frente al mundo y que sobre dicha sensibilidad se establecen unas certezas que marcan la evolución y la historia de los dispositivos. En el caso del documental, como aparato estético, el polo de la sensibilidad estaría dado por las dimensiones ontológica y mecánica, que dan como resultado una certeza que nos atrevemos a postular como una premisa de objetividad. Esta última, a su vez, determinó un discurso hegemónico acerca de lo que debía entenderse por documental en los ámbitos de la producción y la recepción.

Estos límites liberaron al cine de ficción de la obligación del registro, y lo dejaron, al igual que en el caso de la literatura, frente al problema de la verosimilitud; esto obligó al documental a asumir la responsabilidad del registro de la realidad. Con el documental, el discurso de lo cinematográfico 
establece, entonces, una especie de pretensión objetiva (valga decir, sin la intermediación del realizador) para que, supuestamente, la realidad desfile directamente ante el lente de la cámara, y configura lo que podría denominarse el paradigma original del documental. Ya en su libro Memorias de un cineasta bolchevique, Dziga Vertov (2011) aspiraba a que la cámara sirviera para reemplazar la subjetividad que yace en el ojo del realizador.

Sin embargo, esa pretensión de objetividad se vería confrontada con las decisiones subjetivas del qué se mira y cómo se mira, además de la postura ideológica del documentalista sobre el mundo efectivo. Por eso, el cine de lo real se debatió entre la pretensión de objetividad y la estructura narrativa que consolida la obra como resultado, ya que, como plantea Bill Nicholls, "la realidad no es suficiente para tener un documental" (2011, p. 98). Esto significa que el documental está siempre un paso más allá del registro de la realidad.

Inquirir por la condición de las imágenes filmicas obliga a preguntarse cómo la expresividad y la narración (a lo que también está sujeto lo cinematográfico) determinan esas imágenes y alteran aquello que aparece como una huella del mundo al que hacen referencia. Si bien para teóricos como André Bazin (citado en Quintana, 2013) el cine solo puede entenderse como un arte de la realidad y sus imágenes como un rastro material desde el cual es posible revelar la verdad del mundo, otros pensadores, como Rudolph Arnheim (citado en Quintana, 2013), plantearon que lo cinematográfico trascendía la reproducción de la realidad para convertirse en la expresión creativa del realizador.

Así se instaura una serie de interrogantes sobre cuál es el papel de la cámara en el momento de proponer esa especie de relación entre las cosas y su imagen; cuáles son las implicaciones del corte que imponen los límites del encuadre, la definición y la forma de los elementos que allí aparecen; cómo obedecen a una decisión estética e ideológica de quien tiene la cámara, y no a un puro registro empírico, sino a una suma de elementos de significación distintos; entonces, ¿es posible hablar de realidad cinematográfica?, ¿cómo asumir el problema de la realidad: de qué estamos hablando cuando hablamos de realidad?

\section{El giro lingüístico}

Esta inquietud por la realidad continuó desarrollándose a lo largo de la primera mitad del siglo xx en múltiples disciplinas del saber humano y, sobre todo, en cuanto a lo que aquí nos concierne, en el seno de los estudios del lenguaje y las discusiones sobre el arte y lo documental. 
Por el lado de la filosofía del lenguaje, vale la pena mencionar, a manera de ejemplo, nociones como la de juego de lenguaje de Wittgenstein (1992) o la del lenguaje como morada del ser, en el caso de Heidegger (1970), antecedentes de aquello que en la década del 60 se consolida con el nombre de giro lingüístico. En el caso de Wittgenstein, jugar con el lenguaje es crear relaciones sociales; en otras palabras, sabemos qué es el amor o la política en la medida en que reconocemos para cada caso una forma particular de definirlas, decirlas y actuarlas; en una palabra: vivirlas. Por su parte, reconocer que el ser humano vive en su lenguaje es afirmar que no es un mero instrumento para nombrar el mundo, sino que es lo único que el ser humano posee para crearlo y transformarlo.

Estos pensadores, entre muchos otros, fueron los precursores de lo que, en 1964 Gustav Bergman, según lo indica Richard Rorty (1990), denominó giro lingüístico para referirse a una tradición que asumía como centro de las reflexiones al lenguaje en cuanto generador y transformador de aquello que llamamos realidad; esto le otorgó dignidad y reconocimiento a un pensamiento que, como anunciamos antes, empezó con Nietzsche, pero que solo recibió aceptación oficial casi un siglo después. La noción de giro lingüístico actúa, entonces, como un concepto sombrilla que aglutina las preocupaciones conceptuales de diferentes perspectivas como la semiótica, el estructuralismo, la filosofía del lenguaje o la pragmática anglosajona, cuyas repercusiones impactaron directamente la forma en que entendemos hoy la realidad. Como síntesis, asumimos aquí el postulado de Rafael Echeverría (2002) cuando afirma acerca de la realidad lo siguiente: "No sabemos cómo las cosas son. Sólo sabemos cómo las observamos o cómo las interpretamos. Vivimos en mundos interpretativos" (2002, p. 40).

Siguiendo el hilo de la reflexión, tal como lo propusimos en el primer apartado, creemos que existe un nexo entre los pensamientos de los filósofos y teóricos del lenguaje con las rupturas y nuevas perspectivas que se generaron por la misma época en el terreno de las reflexiones artísticas. Dicho de otra manera, proponemos que ese vuelco es extrapolable al ámbito artístico (un giro artístico), cuyo epítome es el arte pop, particularmente el caso de Andy Warhol con su escultura Brillo soap pads boxes de 1964. Estas obras, que toman elementos que en apariencia pertenecen al orden de lo vulgar y les confieren estatus de arte, introducen una fractura en la linealidad de la historia del arte porque van en contravía del presupuesto fundamental de lo excelso presente en las Lecciones de estética de Hegel (1989), discurso imperante hasta entonces. A lo anterior es a lo que Arthur Danto (2010) denomina el fin del arte:

Decir que la historia terminó es decir que ya no existe un linde de la historia para que las obras de arte queden fuera de ella. Todo es posible. Todo puede 
ser arte. Y, porque la presente situación no está esencialmente estructurada, ya no podemos adaptarla a un relato legitimador (2010 p. 137).

\section{El giro de lo documental}

Por esta misma época, en el ámbito del cine, aparece la idea de modernidad, entendida como una ruptura con la sintaxis del cine clásico; en el caso particular del documental, dicha ruptura se relaciona con el cinema verité francés y el cine directo estadounidense. Si bien ninguna de las dos tendencias implica una radical escisión con respecto a la pretensión fundante de lo documental, sí evidencian unos cambios de orden narrativo y conceptual.

En lo que atañe a la narración, estas películas incorporan toda la gramática propia de la modernidad filmica y por primera vez, como lo expone María Luisa Ortega (2008), "el documental, la ficción y el experimental difuminaban fronteras y encontraban vasos comunicantes quizás no tanto en el estilo como en el método, antes en los caminos a transitar que en los fines últimos de sus prácticas" (2008, p. 19). En cuanto a lo conceptual, la preocupación en los años 60 parece que ya no es la realidad, pues si para los nuevos discursos de la filosofía la realidad era una construcción lingüística, entonces el nuevo camino para el documental no se hallaba en la representación de la realidad, sino en la pretensión de acercarse a la verdad del mundo que recreaba. De suerte que si por un lado se hibridaban las técnicas de la ficción y el documental, por el otro lo documental "se consagraba a una paradoja: las circunstancias artificiales podían sacar la verdad oculta a la superficie" (Barnouw, 2005, p. 17).

Los cambios socioculturales y políticos de la década del 60 (las llamadas revoluciones contraculturales) se convirtieron en el escenario propicio para que el arte se ocupara del fin de las utopías que la Modernidad había sostenido para el desarrollo de Occidente. La caída de los grandes relatos, de las promesas de bienestar, progreso y felicidad, generó una inestabilidad tal en todos los ámbitos de la vida social e intelectual que, para el caso que nos ocupa de lo documental, puede sintetizarse de la siguiente manera:

El cine de los años 60 que pugnaba por desembarazarse del naturalismo o el realismo abriría resquicios para que en ellos se colara lo incontrolado, un azar en los métodos de rodaje que daban al traste igualmente con la gramática del montaje clásico, teniendo que inventar lógicas nuevas para lidiar con los tiempos y las acciones concretas que ahora se revelaban en el proceso; a una nueva forma de concebir la práctica fílmica como un proceso de investigación abierto a los "hallazgos" y la epifanía del azar (Ortega, 2008, p. 21). 
Estas nuevas formas de lidiar con el azar, lo inestable y la constante pregunta por la verdad son la antesala de lo que Lipovetsky y Serroy (2009) denominan la era hipermoderna. Época en la cual aparece el concepto de no ficción como máxima prueba de inestabilidad, a tal punto que al no saber cómo definir el meollo de lo documental, se opta más bien por un concepto negativo que poco aclara. Pareciera que en cuanto el término canónico de documental se vacía de sentido ante estos cambios (ya no puede defender la pretensión de retratar miméticamente la realidad ni la idea de una verdad absoluta), se hacen evidentes las fronteras porosas entre ficción y documental (recursos narrativos, técnicos y estéticos compartidos); por lo tanto, ante la falta de claridad acerca de lo que el documental es, surge en los ámbitos académicos la necesidad de, por lo menos, definir y nombrar (otra vez el problema del lenguaje) la única certeza que se tenía: que no era ficción.

En consonancia con lo que hemos venido desarrollando hasta aquí, si nos preguntamos a esta altura de la reflexión por un antecedente que dé cuenta de este nuevo giro en la cuestión documental, es decir, por un ejemplo que evidencie lo que estamos discutiendo, este puede hallarse en la aparición de un caso extraño para las taxonomías del momento, híbrido de ficción y documental que desestabilizó no solo el ámbito documental, también el de la ficción: The thin blue line, de Errol Morris (1988).

El estreno de la cinta causó tal incertidumbre que los miembros de la Academia de los Óscar se negaron a incluirla en su lista de nominados de ese año porque no tenían la certeza de que lo que tenían ante sus ojos fuera un documental. A su vez, cuando la película se exhibió en diversos festivales del mundo, la pregunta más recurrente para el director, de la crítica y la prensa especializada, consistía en tratar de entender por qué eso era un documental. Para sorpresa de los concurrentes, el director afirmaba que carecía de respuesta para esa pregunta porque eso no formaba parte de su preocupación.

En la película, Morris se ocupa del caso de Randall Adams, quien para el momento del estreno estaba en el pabellón de la muerte por haber sido hallado culpable del asesinato de un policía en 1976. Lo interesante y novedoso para la época es que, por primera vez, como lo plantea Joseph María Catalá (2010), un texto documental no parte del mundo referencial como base de su relato, pues no había imágenes de la noche en que acaecieron los hechos, por lo que Morris recurre a crearlas con los recuerdos de los testigos, y, por consiguiente, parte de lo que vemos en pantalla es una re-creación, una invención. 
Si en el documental clásico había una coincidencia entre el tiempo de rodaje y el tiempo de lo rodado (lo que suponía precisamente la objetividad de lo documental y la ilusión de captura de la realidad), en el caso de The thin blue line esta coincidencia temporal se fractura porque la cámara no estaba presente en el aquí y ahora de los hechos. El único recurso que queda es recurrir a los recuerdos de quienes alli estuvieron. Sin embargo, mientras transcurre la trama y el espectador atiende a las diferentes versiones de los testigos, puede notar cómo hay pequeñas variaciones en las perspectivas de cada uno, con lo que se pone en evidencia no solo que los recuerdos son una construcción, una suerte de ficción, sino que, en esa medida, la realidad de esa noche es tan múltiple como la multiplicidad de voces que la cuentan.

Las fronteras entre ficción y no ficción se han roto, de tal suerte que "no hay nada que distinga absoluta e infaliblemente el documental de la ficción" (Nicholls, 2011, p. 55), y la promesa del registro del mundo real comienza a resquebrajarse. En ese momento distintos teóricos empiezan a hablar de no ficción como una nueva manera de aproximación al mundo real, como una nueva promesa de representación para la cual el término documental ya no es suficiente, como última esperanza para devolver, por medio del lenguaje, la estabilidad perdida.

\section{La irrupción de la subjetividad en la pretensión estética y poética del documental}

Esta última posición, a nuestro modo de ver, constituye una salida (fácil y cómoda), si se nos permite el término, que evade el problema central acerca de por qué es necesario hoy no solo seguir teorizando sobre lo documental, sino reivindicar su ontología. Por lo tanto, este último apartado, a manera de conclusión, desarrolla tres propuestas: la primera, el recorrido anterior demuestra que la pretensión de objetividad heredada del positivismo decimonónico poco a poco cedió el lugar a lo que nos atrevemos a denominar como las formas contemporáneas de la subjetividad. Segundo, y como consecuencia de esto, los códigos narrativos y genéricos se trastocan hasta generar nuevas posibilidades narrativas y técnicas tanto para la creación como para la percepción y recepción del objeto estético documental. Tercero, tal reconfiguración desencadena el desplazamiento de los linderos tradicionales entre ficción y documental y permite hibridaciones y préstamos mutuos, lo cual no significa que las diferencias desaparezcan, sino que es necesario rastrearlas en otro lugar: en los alcances referenciales, parafraseando a Ricœur (2006), de una y de otro en cuanto que posibilidades del lenguaje; en otras palabras, y como lo anuncia el título de este ensayo, las pretensiones poéticas del acto creativo. 
Abordemos el primer aspecto tomando como punto de referencia a Jonas Mekas (1972), quien en los años 70, con Reminiscencias de un viaje a Lituania, subvierte el enfoque documental al incluir en su relato la perspectiva intimista del diario, dejando así de lado la narración colectiva de grandes hechos observada desde la tercera persona o, como lo denominan varios teóricos, la voz de Dios. Este filme se erige como referencia obligada que trastocó la mirada de los nuevos realizadores sobre la importancia de los relatos del yo, de las historias personales o, si se quiere, como sucedió en el caso de la sociología, hacia la microesfera de lo cotidiano.

Otro ejemplo de cómo se fueron imponiendo este tipo de subjetividades lo encontramos en Jean-Luc Godard (1988-1998), quien en la década de los 90, justo cuando se conmemoraba el primer centenario del cine, presenta sus Histoire(s) du cinema. Para el caso que nos atañe, esta obra resulta prototípica, pues en ella el director francés revisa la historia del cine y la expone a manera de ensayo: en primera persona la comenta, la analiza, la critica como si estuviéramos ante un gran editorial visual. Además, el realizador no solo funge como instancia narrativa o como comentarista: también, apoyado en la autorreferencialidad y autorreflexividad metaficcionales (Ardila Jaramillo, 2014), se incluye en el mundo diegético como si fuera uno más de sus personajes.

Los casos anteriores demuestran nuestro segundo punto: la inflexión no solo en la obra posterior de los autores referidos, sino en la profunda transformación que ha derivado en una vasta producción filmica documental que en los últimos años del siglo XX, y lo que va del XXI, se ha tomado los festivales más importantes del mundo y los circuitos de exhibición con historias de este tipo.

La llegada de la subjetividad al mundo de lo documental (declarada y asumida sin ambages), lo emancipa de la preocupación por la objetividad y le permite asumir como recursos propios lo que hasta entonces se suponía como exclusivo de los códigos genéricos de la ficción. En cuanto lo que se pone en escena ya no son los hechos en sí mismos, sino la interpretación personal que los hace dignos de evocación, se reconoce que la memoria es un acto creativo ficcional y, en consecuencia, los recursos de escenificación aparecen como el camino viable y deseable para representar lo vivido.

En este nuevo paradigma, al decir de Goodman, "la verdad, lejos de ser un ama solemne y severa, es una sirvienta dócil y obediente" (1990, p. 38). A partir de esta afirmación, llegamos a nuestro punto final: la realidad, y, por tanto, la noción que de ella tenemos, no es más que el resultado de una serie de proposiciones que nos permiten construir, para los otros y con los otros, eso que llamamos las verdades del mundo. De allí que en 
múltiples disciplinas que abarcan desde la semiótica (Eco, 1993), pasando por los estudios literarios (Ryan, 1997) y visuales (Mitchell, 2009), hasta la filosofia del lenguaje (Goodman, 1990), por mencionar solo algunas, se prefiera hablar hoy en plural de mundos y de visualidades, sobre todo de mundos posibles y visualidades posibles, porque lo son en el lenguaje que los crea y los hace accesibles para otros en forma de parcela compartida de un mundo común que, en un acto de fe, denominamos realidad y mundo en singular.

\section{A manera de conclusión}

Nuestra propuesta es que lo documental no radica hoy en la posibilidad o imposibilidad de reflejar la realidad como una evidencia fáctica, sino en seguir recordándonos que, aunque aquella es una construcción, es en esa construcción en la que amamos, nos odiamos, nos hacemos sublimes o abominables porque, en definitiva, es en esa ilusión (de la que nos hemos olvidado que lo es) en la que fundamos nuestra esperanza de hallar nuestra certeza de ser y estar en el mundo.

Lo que sostenemos, entonces, es que no hay una diferencia sustancial entre la ficción y lo documental. Sin embargo, a pesar de que asumimos a ambos como resultado de la creación discursiva y que, en términos del relato, comparten códigos y técnicas de representación, postulamos que lo que los diferencia se halla en otro lugar: en el problema de la referencia a la que apuntan ambas formas.

La ficción instaura sus posibilidades de verosimilitud en una referencia interna, es decir, hacia adentro de sí misma en un marco de verdades que subyacen al mundo narrativo y que lo son solo allí, aunque en nuestro mundo fáctico no lo sean o vayan inclusive en contravía de nuestros marcos de referencia; verbigracia, un extraterrestre que, a causa del cambio de atmósfera entre su lugar de origen y la Tierra, desarrolla ciertas habilidades que lo convierten en el héroe salvador de nuestro planeta: Supermán. Entonces, en cuanto la referencia ficcional de las cosas representadas es interna, los mundos ficcionales solo dependen de sí mismos para existir, siempre y cuando sean coherentes con las reglas de juego que le proponen al lector y, en consecuencia, respeten y satisfagan el pacto ficcional que ese mundo propone.

En cambio, en lo documental el mundo representado depende no solo de la coherencia interna del relato, sino, además, y esta es nuestra declaración, de poner de manifiesto su referencia externa: en otras palabras, a pesar de que lo documental comparta con la ficción todos sus artificios, solo puede ser documental porque existe aquello que, siguiendo a Ricœur (1999), 
denominamos archivo, es decir, la prueba de que la cosa contada fue cosa vivida, cosa acaecida. Como diría Barthes (2009) con respecto al ser en sí de la fotografia: "Esto ha sido" (2009, p. 91).

En este sentido, la concomitancia del documental con las cosas vividas hace que este, a diferencia de la ficción, solo pueda prometernos pasado y memoria. Una memoria (otra vez Ricœur) de aquello que es digno de ser recordado como individuos y como sociedad. Una memoria que, como acto imaginativo y creativo del documentalista, construye un mundo posible de un pasado simulado y evocado que atestigua lo que ha sido en cuanto lo ha representado.

En síntesis, aquello que líneas atrás designábamos con el término de referencia externa, condición inexorable de lo documental, depende de las modulaciones del discurso de cada época sobre aquello que nombramos como lo real. En términos de Todorov: "Una sociedad elige y codifica los actos que corresponden más exactamente a su ideología" (1988, p. 39). Así pues, podemos concluir que el documental, si aspira a algo semejante a dar cuenta de la realidad, lo será en cuanto acto poético y estético. Acto creativo que seguirá mudando sus formas a la par que cambien las maneras en que negociamos nuestros acuerdos discursivos con los que pretendemos crear y creer en nuestra realidad.

\section{Referencias}

Ardila Jaramillo, A. C. (2014). El segundo grado de la ficción. Fondo Editorial Universidad EAFIT y Universidad de Antioquia.

Barnouw, E. (2005). El documental. Historia y estilo. Gedisa.

Barthes, R. (2009). La cámara lúcida. Paidós.

Catalá, J. M. (2010). Panorama desde el puente, nuevas vías del documental. En A. Weinrichter (Ed.), .doc. El documentalismo en el siglo XXI (pp. 33-52). Festival Internacional de Donostia.

Danto, A. (2010). Después del fin del arte. Paidós.

Déotte, J. L. (2007). ¿Qué es un aparato estético? Benjamín, Lyotard, Ranciére. Metales pesados.

Echeverría, R. (2002). Ontología del lenguaje. Dolmen.

Eco, U. (1993). Lector in fabula. Lumen.

Foucault, M. (2007). La arqueología del saber. Siglo XXI Editores.

Godard, J. L. (Dirección). (1988-1998). Histoire(s) du cinema [Película cinematográfica]. Gaumont.

Goodman, N. (1990). Maneras de hacer mundos. Visor.

Hegel, G. W. F. (1989) Lecciones de estética. Ediciones 62.

Heidegger, M. (1970). Carta sobre el humanismo. Taurus.

Lipovetsky, G. y Serroy, J. (2009). La pantalla global. Anagrama. 
Mora, A. (2021). El Desprendimiento de la realidad: el cambio de paradigma en las imágenes de lo documental. [Tesis de Doctorado, Universidad EAFIT].

Mekas, J. (Dirección). (1972). Reminiscencias de un viaje a Lituania [Documental]. Vaughan Films.

Mitchell, W. J. T. (2009). Teoría de la imagen. Paidós.

Morris, E. (Dirección). (1988). The thin blue line [Documental]. Miramax.

Nicholls, B. (2011). La representación de la realidad. Paidós.

Nietzsche, F. (2011). Escritos de juventud. En Obras completas (Vol. I). Tecnos.

Ortega, M. L. (2008). Cine directo: notas sobre un concepto. En M. L. Ortega y N. García

(Eds.), Cine directo: reflexiones en torno a un concepto (pp. 17-27). T\&B.

Quintana, A. (2013). Fábulas de lo visible. Acantilado.

Ricœur, P. (1999). Historia y narratividad. Paidós.

Ricœur, P. (2006). Del texto a la acción. Fondo de Cultura Económica.

Rorty, R. (1990). El giro lingüístico. Paidós.

Ryan, M. L. (1997). Mundos posibles y relaciones de accesibilidad. Una tipología semántica de la ficción. En L. Doležel y A. Garrido (Comps.), Teorías de la ficción literaria (pp. 181205). Arco Libros.

Sontag, S. (2007). Sobre la fotografía. Alfaguara.

Todorov, T. (1988). El origen de los géneros. Arco Libros.

Vertov, D. (2011). Memorias de un cineasta bolchevique. La Marca Editora.

Wittgenstein, L. (1992). Tractatus lógico-philosophicus. Alianza. 